\title{
CLOUD CONNECTED DUST BINS WITH PREDICTIVE ANALYTICS USING MACHINE LEARNING
}

\author{
Diksha H. Chiwande \\ Department of Electronics and Communication, \\ Ballarpur Institute of Technology Ballarpur, India
}

\author{
Prof. Ashish Manusmare \\ Department of Electronics and Communication, \\ Ballarpur Institute of Technology Ballarpur, India
}

\begin{abstract}
This work is going to make a shrewd residue receptacle, which can be utilized by authorities to gather waste deny. There are civil administrations given to gather trash from slurry filled territories. The idea of 'AI' is utilized to gather data about the waste age rehearses around there and in this way can be measured later on for the waste created. In this examination paper, we proposed to plan and execute a successful Cloud Connected Dustbins with Predictive Analytics Using Machine Learning in context of creating nations utilizing Simple Linear Regression calculation for brilliant basic leadership framework. The principle target of the venture is to grow profoundly versatile framework for the current wastereceptacles. What's more, there has additionally been ceaseless investigation of information which will be pushed into the type of mists. When the waste level in the dustbin will be passed, the email cautions and the instant message will be sent to the concerned experts subsequent to intersection the edge fixed by the Authority. AI calculations apply $\mathrm{o}$ information gathered and prepared on which results are found. These models are prepared for long time to react to new information and them it conveys the outcomes we need with more exactness. This will basically set aside the time and cash of the Authority. This will likewise lessen air contamination in the zone and avert.
\end{abstract}

Keywords: ESP 8266 Wi-Fi Module, Ultrasonic Sensor, IR Sensor, Gas Sensor, Humidity \& Temperature Sensor, Machine learning

\section{INTRODUCTION}

According to the United Nations report by 2025, the population will increase by $20 \%$ and the population will reach 8 billion. Due to such increase in population, the demand and consumption of goods will increase, which will increase the waste production at the same rate. Considering the current methods of managing waste in the city, there will be no right to the technology required for such large scale waste management system. Dustbins are kept at various places in the city. It is their duty to check and clear the waste in the dustbin at regular intervals. If there is a delay, there may be some possibility of reducing the garbage. This can cause bacteria and viruses to grow. It should be kept in mind that $75-80 \%$ of solid waste management budget is spent on collection and transfer of garbage. It is a waste, time-consuming, and costly approach to check every garbage in large cities. Today the Indian authorities handle about 3 billion tons of garbage annually, in which about 150 million tons of waste are threatened by humans and animals. Therefore, handling and removing this waste effectively minimizes environmental damage. Waste management is one of the basic concerns of the modern era.

In this research, we proposed to plan and actualize a successful Cloud Connected Dustbins with Predictive Analytics Using Machine Learning in context of creating nations like India, Bangladesh and so forth., utilizing Simple Linear Regression calculation for keen basic leadership framework. The fundamental goal of the venture is to grow profoundly adaptable framework for the current wastecontainers, with the goal that the degree of the trash within the receptacles can be detected and told to the concerned expert for accumulation. AI is a sub field of AI. The motivation behind $\mathrm{AI}$ is more often than not to comprehend the structure of the information and to fit the information in the model that is comprehended and utilized by individuals. Despite the fact that PC training is one region in the field of software engineering, it is unique in relation to conventional processing points of view. In conventional calculation, calculations are a lot of customized guidelines unmistakably used to gauge through PC or to take care of the issue. AI calculations enable you to prepare PC on information info and utilize factual investigation to quantify the yield of qualities that happen in a specific range. Therefore, the PC machine makes it simple to mechanize the basic leadership procedure dependent on information contribution, to display models from test information.

Today, any innovation is utilized to gain from AI. Face discovery innovation enables the internet based life stage to enable clients to share labels and photographs of companions. Optical Character Recognition (OCR) innovation changes over a picture of content into a versatile sort. Proposals motor fueled by $\mathrm{AI}$ to recommend what motion pictures or TV projects to watch beside client inclinations. Self - driving 
vehicles that are subject to AI to explore can before long be accessible to the clients. Things are either sensors or actuators. A sensor is something that educates us concerning our condition. Think about a temperature sensor, or even the GPS recipient on your cell phone. Actuators are something that you need to control, things like fan, lights, siphons, and outlets. The "Web of Things" unites everything and enables us to interface with our things. For instance, you could have your fan control itself dependent on where you're found. The Internet of Things (IoT) is a situation wherein articles, creatures or individuals are given one of a kind identifiers and the capacity to move information over a system without expecting human-to-human or human-to-PC association. IoT has advanced from the assembly of remote advances, miniaturized scale electromechanical frameworks and the Internet. A thing, in the Internet of Things, can be an individual with a heart screen embed, a ranch creature with a biochip transponder, a car that has worked in sensors to caution the driver when tire weight is low or some other characteristic or man-made article that can be doled out an IP address and furnished with the capacity to move information over a system. Up until now, the Internet of Things has been most intently connected with machine-to-machine correspondence in assembling and power, oil and gas utilities. Items worked with Machine to Machine correspondence capacities are regularly alluded to as being keen.

\section{PROPOSED WORK}

Often we see in our city that there is a waste or dustbin overflow in public place. It crates unhygienic condition for people. Also, it creates ugliness to that place. At the same time bad smell is also spread. To avoid all such a situation we will implement a Cloud Connected Dust Bins with Predictive Analytics Using Machine Learning.

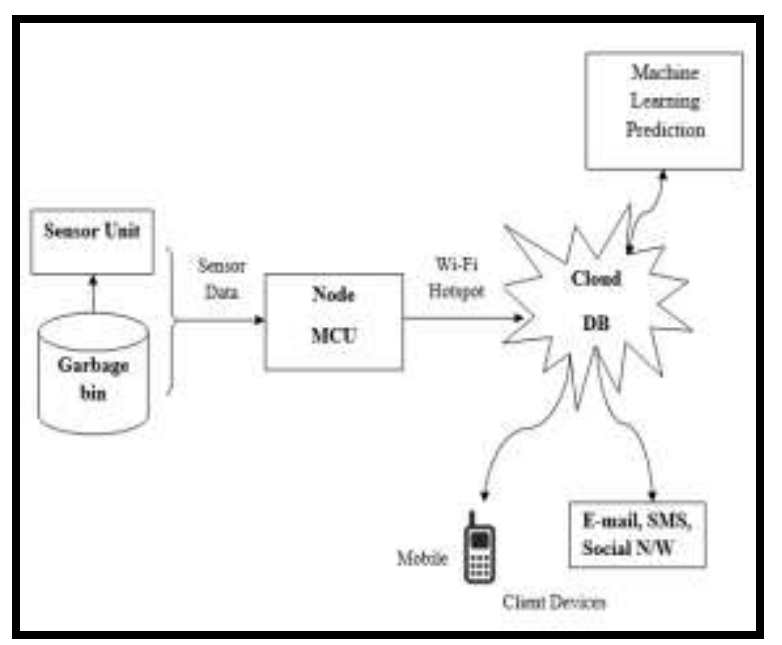

Figure 2.1 Block Diagram for Proposed System
The block diagram of the proposed system is shown in above figure. The bins installed with sensor unit send the information to the server through wireless communication using $\mathrm{Wi}-\mathrm{Fi}$ module Node MCU (ESP-8266) which needs Wi-Fi connection that provides peer to peer connection. The ultrasonic and IR sensors are installed in the dustbin which senses the level of waste in it. Once a threshold is crossed, the data is sent to node MCU which sends an alert via SMS and Email. This data is then sent to the cloud via $\mathrm{Wi}-\mathrm{Fi}$ module. The data is then further sent to machine learning platform for training the data set, real time monitoring of waste and future prediction of the waste generation pattern in the given area.

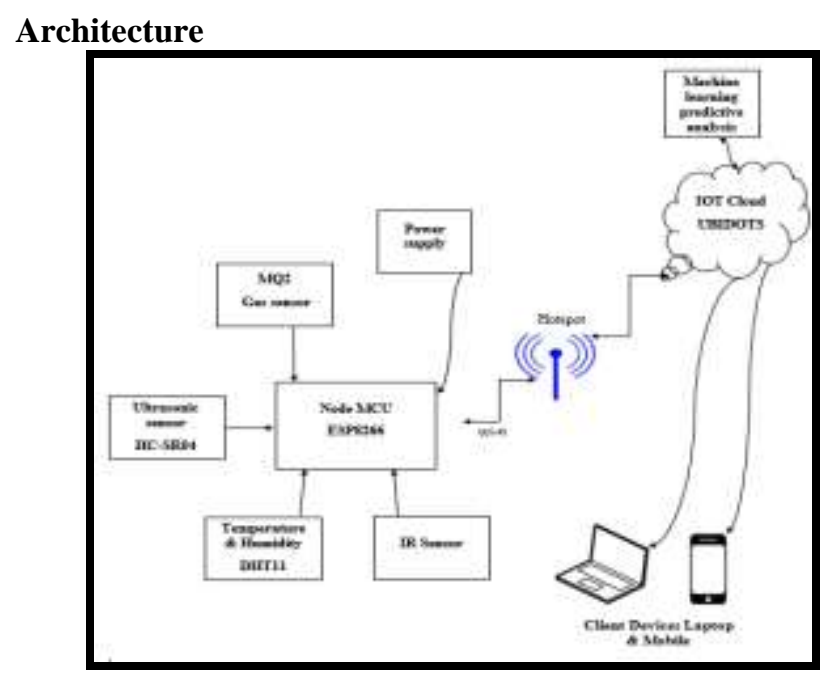

Figure 2.2 Architecture of proposed system

In this framework we are observing the degree of containers and making out of waste utilizing cloud and AI. Our primary objective of proposed this framework to remotely screen the framework and sends speedy notice to power which is diminish the flood of containers. In figure Node MCU ESP8266 in assembled Wi-Fi module are put in top of the dustbin which are associated with the different sort of sensor. The power supply is given to Node MCU. In the dustbin four sort of sensor are put, for example, ultrasonic sensor, IR sensor, Temperature and dampness sensor, gas sensor and so forth, The hub MCU ESP8266 is utilized to interface the sensor unit. Sensor unit demonstrate the distinctive degree of the measure of thee trash gathered in dustbin which is put in an open territory. The cloud is additionally created to screen the ideal data identified with the trash for various chose area. This will deal with the trash accumulation proficiently. For level indicator comprise of ultrasonic sensor which is utilized to identify the degree of the trash in the dustbin. The fill level sensor will utilized ultrasonic waves for separation estimation. The yield of the level identifier is given to the hub MCU ESP8266. The Node MCU will be additionally interface with the MQ2 gas sensor. The gas level sensor will quantify the 
nearness of gas in the dustbin which has high touchy to methane is a noteworthy bi-result of waste disintegration. It will consider containers which will be filled over $70 \%$ or have any dangerous gas present. Assumed, a receptacle doesn't get filled quicker yet its waste create bi-items like methane which hazardous and shut containers may burst into flames is a hot nation like India thus gas observing is vital. The temperature and stickiness sensor will be additionally interface with the Node MCU ESP-8266. The temperature and mugginess sensor must be utilized to dry and wet waste identification for this reason DHT11 sensor will be utilized. IR sensor is additionally associated with the hub MCU. They are utilized to shut and open the top of the dustbin. Every one of the information are get to the cloud which send a ready warning to customer gadget or specialist. The primary component that contrasts from the other framework is that AI investigation are utilized in the proposed framework. The information gathered from the cloud and apply different kind of AI calculation. The AI idea has been utilized to accumulate data about the waste age propensities in that area that will be created sooner rather than later.

\section{Flowchart}

The process of operation of Cloud Connected Dust Bins with Predictive Analytics Using Machine Learning.

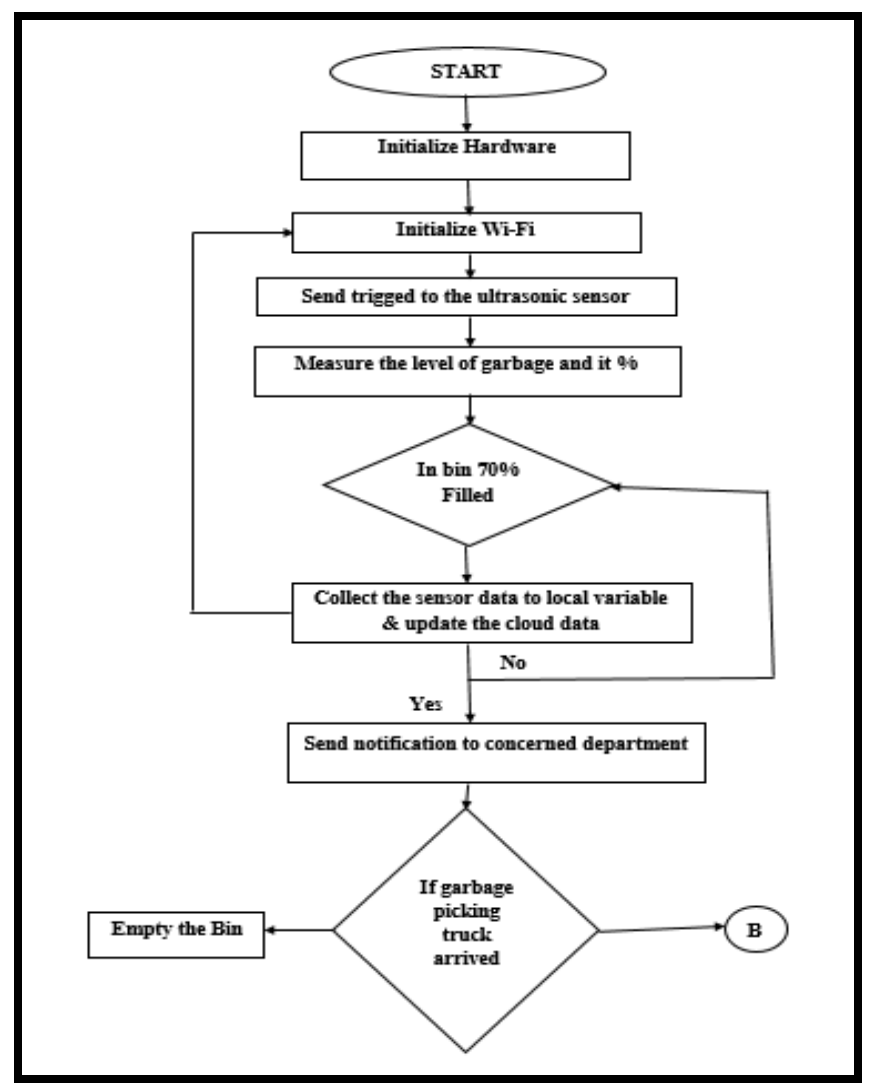

Figure 2.3 (A) Flow chart 1

\section{Flowchart 1}

Figure 2.3 (a) shows the step by step procedure of garbage level monitoring system as follows.

Step 1: Initialize the hardware.

Step 2: Initialize the Wi-Fi.

Step 3: To start the ultrasonic sensor Node MCU will send the trigger pulses to it.

Step 4: Measure the level of garbage inside the Dustbins.

Step 5: The current status of garbage level will be checked by the Node MCU ESP8266, is bin $70 \%$ filled or not?

Step 6: If yes then Node MCU will collect the sensor data to local dustbin and update the cloud data and send the notification to concerned authority, and if bin is not filled up to $70 \%$ then system repeats the step no 5 .

Step 7: After receiving the notification by authority, it will send the garbage picking truck to collect the garbage from the bin, and empty it.

Step 8: If truck will arrive then the bin will be get emptied by them.

Step 9: If truck will not arrive then check the conditions of B.

\section{Flowchart 2}

Now the garbage level is reaches to its $70 \%$ but still if the truck had not arrived then the further conditions is shown in figure 2.4. Now as the bin is continuously getting filled it may get overflowed after some time.

1. If bin is filled $100 \%$ then alert will be send to the higher authorities, and if not, then the level will be continuously checked.

2. After receiving the message by higher authorities, they will send the garbage picking truck and bins will get emptied by them. 


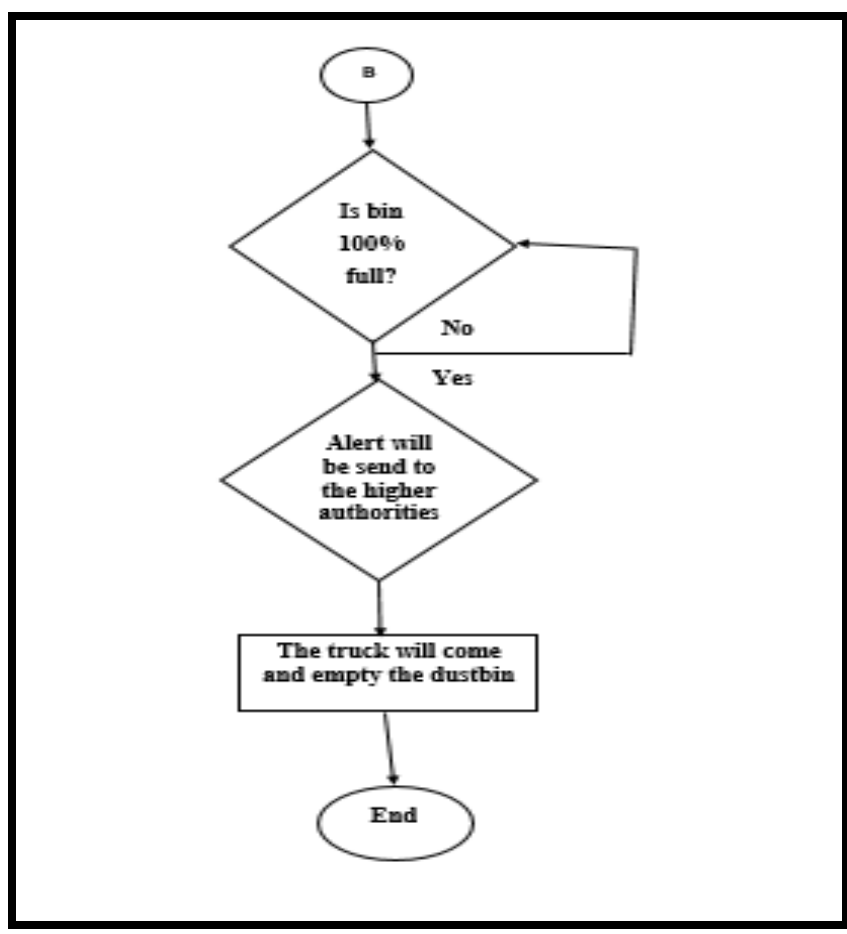

Figure 2.4 Flow chart 2

\section{SOFTWARE IMPLEMENTATION}

UBIDOTS Software The rudiments parts of any Internet of Things application fueled by Ubidots are: Devices, Variables, Synthetic Variables Engine, Dashboards, and Events. Inside this article we will address every one of these ideas as they identify with Ubidots IoT Development and Deployment Platform and how you can all the more likely sort out your Ubidots Apps to best interface with the clients.

\section{Spyder}

Spyder is an incredible logical condition written in Python, for Python, and structured by and for researchers, architects and information examiners.

\section{RESULT}

We have successfully implemented the "Cloud Connected Dust Bins with Predictive Analytics Using Machine Learning" project. In this project we are used two dustbin like D1, D2. We will get the real-time sensor data and upload it on the Ubidots cloud. Thus, we got the real-time data on the cloud. We executed this project as shown in photographs:

\section{Lid Position monitoring}

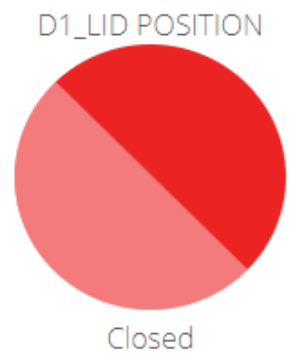

Figure 4.1: when dustbin is closed.

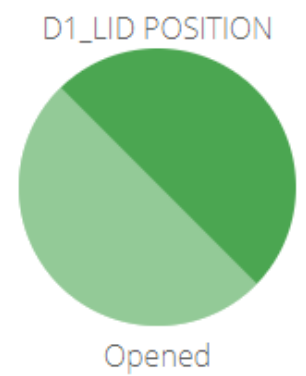

Figure 4.2: When dust bin is opened.

When the dustbin is closed lid position shows Red and dustbin is opened lid position will Green; similarly for D2.

\section{Dust level monitoring}

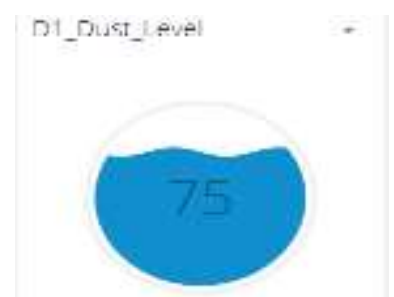

Figure 4.3: D1 crossed 70\% level

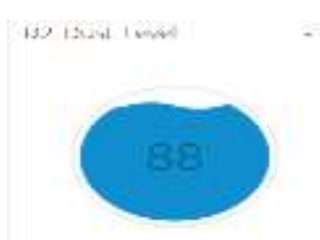

Figure 4.4: D2 crossed 70\% level

Once the level of waste in the dustbin crosses the threshold set by the authorities. The levels of waste in the bins are identified using ultra-sonic sensors. Sensor are used to indicate the level of waste and the sensed data from the sensor are moved to Node MCU. Through Wi-Fi the data are stored in cloud and available space of the bin is viewed. 


\section{Dust and Humidity level and Temperature monitoring} For Dustbin 1:

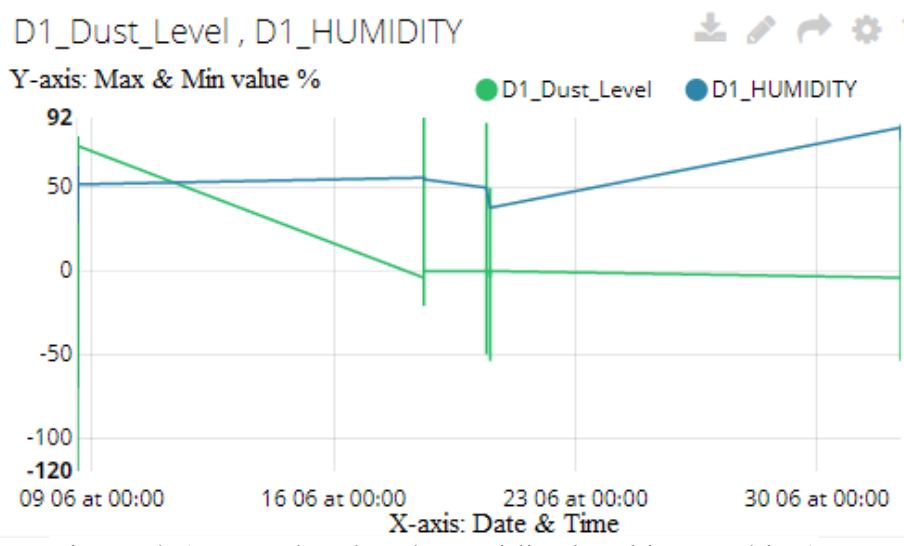

Figure 4.5: Dust level and Humidity level in Dustbin 1

\section{D1_TEMPERATURE}

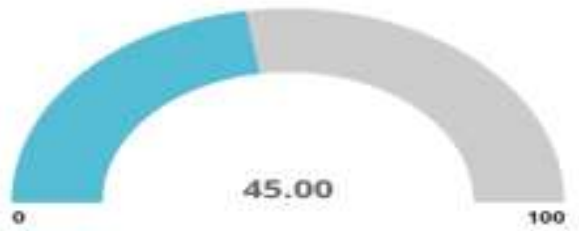

Figure 4.6: Temperature level of Dustbin 1

The Graphical representation of Dust level \& Humidity and Temperature Sensor data of dustbin D1 \& D2. In this Green line shows the dust level \& Blue line shows the Humidity level.

\section{For Dustbin 2:}

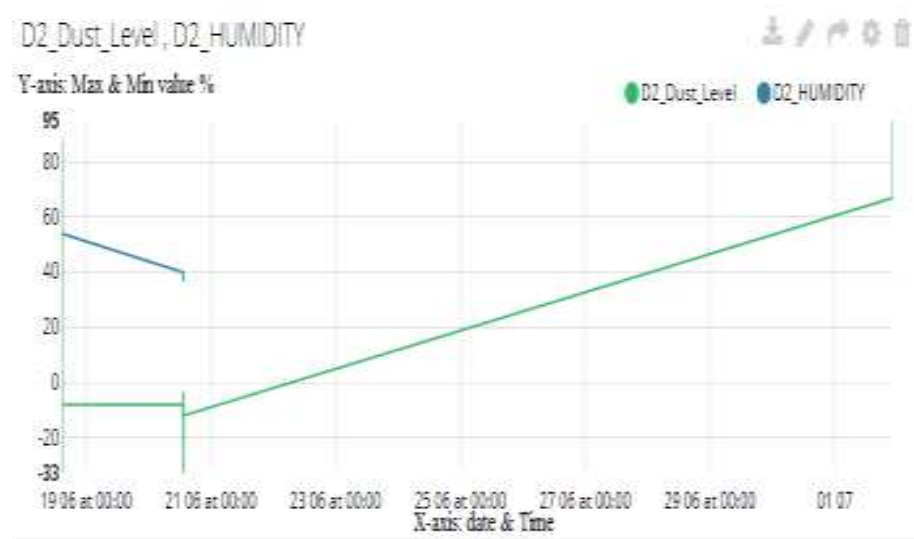

Figure 4.7: Dust level and Humidity level in Dustbin 2

\section{D2_TEMPERATURE}

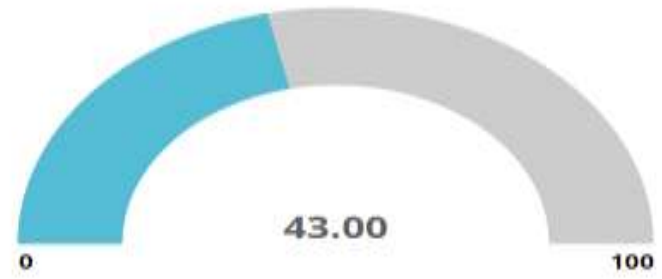

Figure 4.8: Temperature level of Dustbin 2

The bin temperature and humidity \& dust level should be monitored because it may cause the waste in the bin to decompose and cause pungent smell from the bin which may cause many diseases. So that we use a DHT11 sensor to analyze the temperature and humidity of the bin. This can be visualized using cloud.

\section{Smoke Level Monitoring}

D1_SMOKE

Y-axis: Max \& Min value \% $\pm \Rightarrow \Rightarrow$ 배

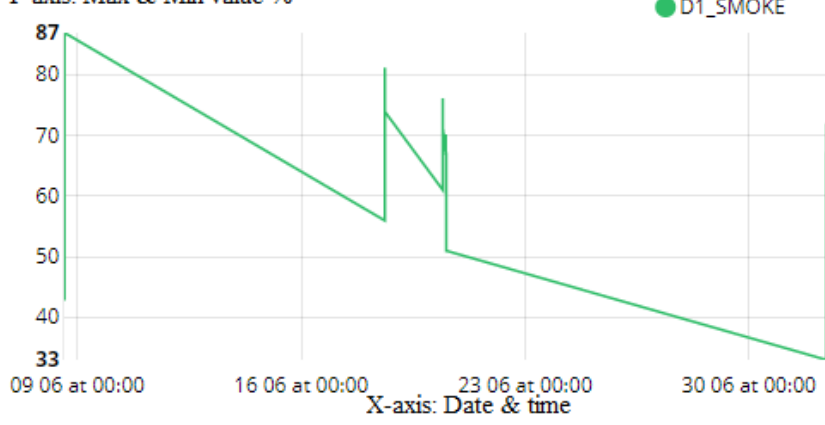

Figure 4.9: Smoke level of dustbin 1

D2_SMOKE

I-des Nax \& M fin whe $2 \%$

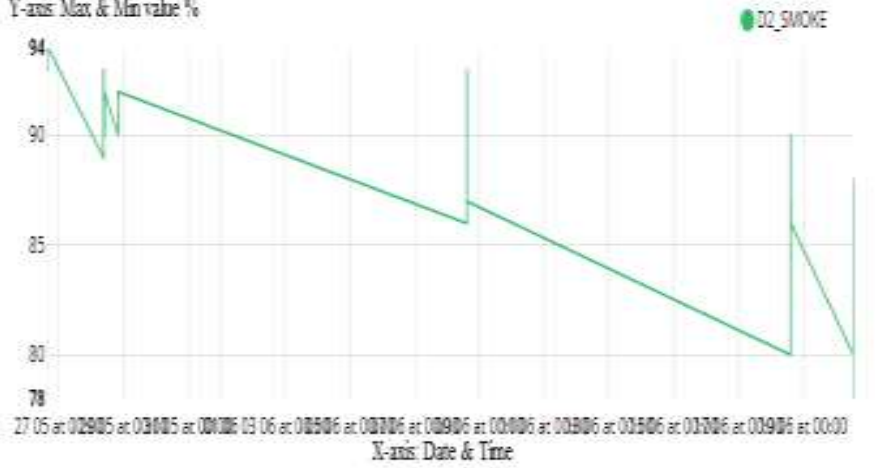

Figure 4.10: Smoke level of dustbin 2

The Graphical representation of Smoke level sensor data of dustbin D1 \& D2. The Green line shows the smoke level. The levels of waste in the bins are identified using ultra-sonic sensors. Gas sensors are placed in the main storage to identify the level of gas present, the data from the gas sensor are sent to the cloud using $\mathrm{Wi}-\mathrm{Fi}$. When the level of gas is high, waste 
can be used as a fertilizer and notification will be sent using cloud.

The E-mail alert and text message, Telegram have also been sent automatically to the concerned authorities.

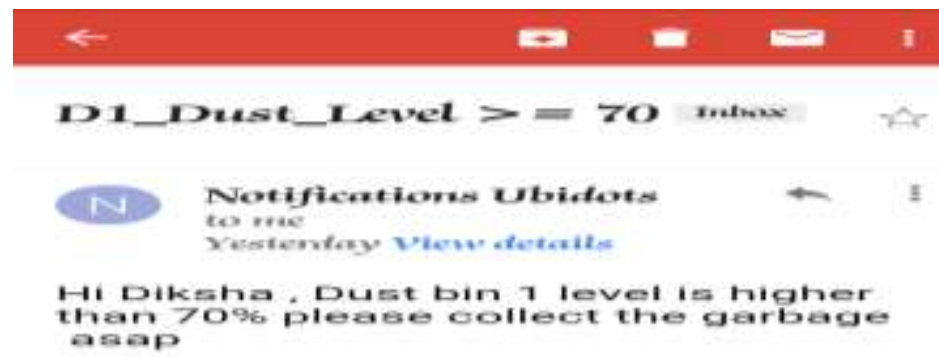

Figure 4.11: The alert E-mail Recived for dustbin 1 When the bins D1 is full, a notification or a E-mail is sent using cloud to the staff in-charge.

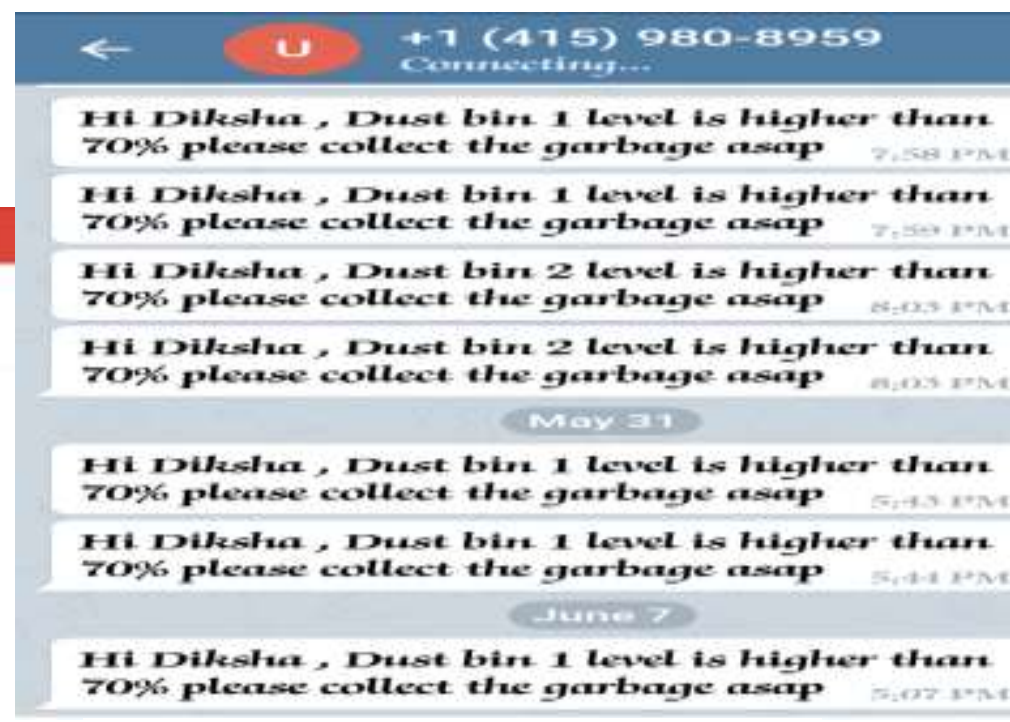

Figure 4.14: The Message received in Telegram apps When the bin D1 or D2 are full, a telegram is sent using cloud to the authority.

\section{世 $\quad \square \quad$ 다}

D2_Dust_Level $>=7 O$ Irubux

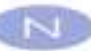

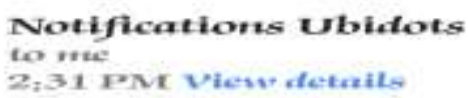

Hi Diksha. Dust bin 2 level is higher than $>0 \%$ please collect the garbage asap

Figure 4.12: The alert E-mail Recived for dustbin 2 When the bins D2 is full, a notification or a E-mail is sent using cloud to the staff in-charge.

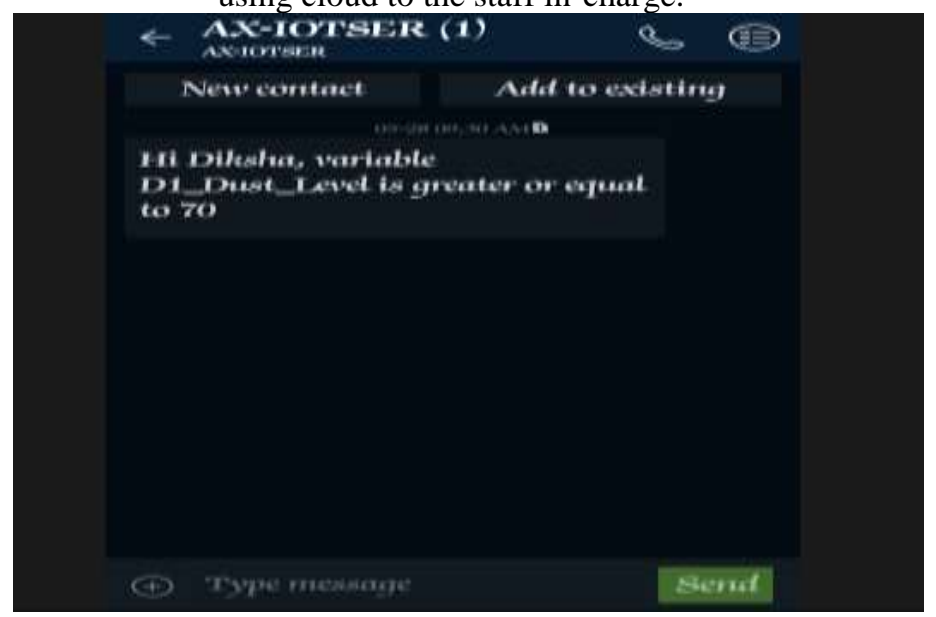

Figure 4.13 The SMS received in Message Box When the bins are full, a notification or a message is sent using cloud to the staff in-charge.

\section{Predicts the amount of waste using machine learning}

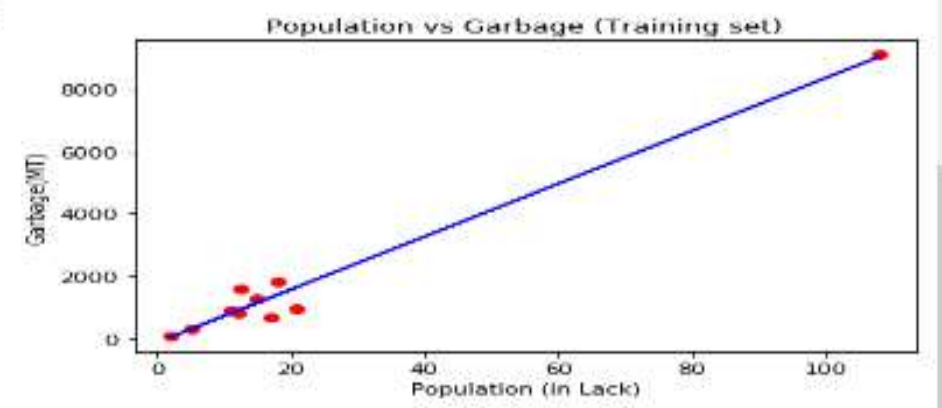

Figure 4.15: Training Set

It also predicts the amount of waste generated in future using machine learning approach by taking data on cloud.

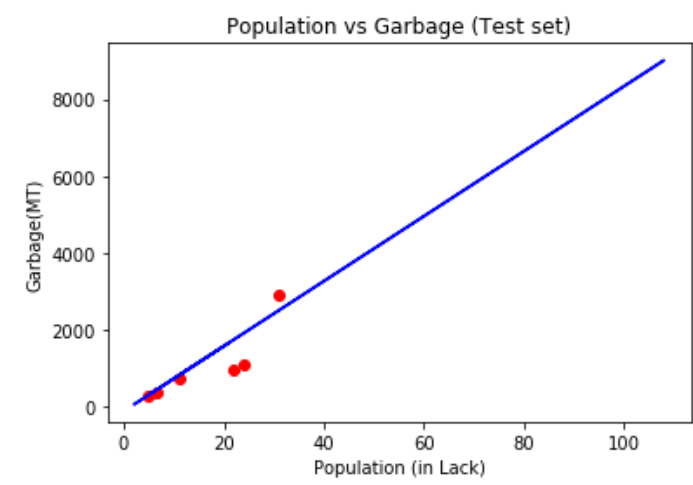

Figure 4.16: Test Set

Graph shows the expected rise in the waste based on population growth in that region in the form of linear plot. 


\section{CONCLUSION \& FUTURE SCOPE}

The proposed framework effectively shows the capacity of continuous observing of waste age rehearses in the city. In case of fulfillment of the container, ready messages are additionally sent to the dependable authorities to get the waste. This will spare both the sum and time spent by the Authority to physically follow all the dustbin. Unsurprising waste age is done precisely utilizing the straightforward direct relapse model for the city. This expectation model will be helpful for deciding the monetary allowance dispensed for the gathering and move of waste in the given region. This will at last lead to a perfect domain which is contamination and infection free.

In future work, Iot control proficiency will be preliminary testicles utilizing sunlight based vitality and the proposed arrangement reached out over numerous city territories to further learn structure adaptability just as improve checking limit. In future, the framework can be moved up to the better discovery of waste by utilizing propelled calculations of AI. In future work, the proposed framework intends to supplant the need of individuals in waste isolation process by utilizing picture handling for waste recognition and arranging dependent on AI with the container ready to explore in a onetime way set by client. This is remarkable, straightforward and expends less power and assets as it requires no mind boggling equipment. In further work incorporates, enhancement of the outcomes and forecast exactness's for different discrete contributions to ongoing. Along these lines this methodology, helps in decreasing contamination levels and over the long haul centers around the improvement of general waste isolation system. In this way, the work is a significant resource for the general public.

\section{REFERENCES}

[1] Cyril Joe Baby,Harvir Singh, Archit Srivastava, Ritwik Dhawan2 and P. Mahalakshmi, (2017) "Smart Bin: An Intelligent Waste Alert and Prediction System Using Machine Learning Approach" - This full-text paper was peer-reviewed and accepted to be presented at the IEEE WiSPNET conference, 978-1-5090-4442-9/17/ 2017 IEEE.

[2] Mokshada V. Patil, Snehal M. Gajbhiye. (2017) “A Review on Internet of Things Based Garbage Bins Detection Systems", Volume 6 Issue 4, April 2017.

[3] J. Gubbi, R. Buyya, S. Marusic and M. Palaniswami, (2013) "Internet of things (IoT): a vision, architectural elements, and future directions",Future Generation Computer Systems Volume 29, Issue 7, September 2013, Pages 1645-1660

[4] K. Ashton, (2009) "That "internet of things" thing", RFiD Journal, vol. 22, pp. 97-114, 2009.

[5] D Vikrant Bhor, Pankaj Morahkar, Maheshwar Gurav, Dishant Pandya, (2015) "Smart Garbage Management
System", International Journal of Engineering Research \& Technology (IJERT), Vol. 4 Issue 03, March-2015.

[6] S.S. Navghane, M.S. Killedar, Dr.V.M. Rohokale, (2016) "IoT Based Garbage and Waste Collection Bin", May 2016.

[7] Ghose, M.K., Dikshit, A.K., Sharma, S.K. - "A GIS based transportation model for solid waste disposal", A case study on Asansol municipality", India.

[8] Guerrero, L.A., Maas G. and W. Hogland,( 2013) "Solid Waste Management Challenges for Cities in Developing Countries Waste Management", Iss.no. 33, 220-232, 2013.

[9] Alexey Medvedev, Petr Fedchenkov, ArkadyZaslavsky, Theodoros, Anagnostopoulos Sergey Khoruzhnikov, ( 2015) "Waste Management as an IoT-Enabled Service in Smart Cities", an International Adjunct Professor at ITMO University since 2012, (C) Springer International Publishing Switzerland 2015, S. Balandin et al. (Eds.): NEW2AN/ruSMART 2015, LNCS 9247, pp. 104-115,.

[10] APA Meghana K C, Dr. K R Nataraj, May 16 Volume 4 Issue 5, "IOT Based Intelligent Bin for Smart Cities", International Journal on Recent and Innovation Trends in Computing and Communication (IJRITCC), ISSN: 2321-8169, PP: 225 - 229.

[11] KasliwalManasi H., SuryawanshiSmitkumar B (2018) "A Novel Approach to Garbage Management Using Internet of Things for Smart Cities". November 2018with33 Reads Conference: I International Conference Technology \& Entrepreneurship In Digital Society, At Moscow Russia.

[12] Vishesh Kumar Kurrel, (2016) "Smart Garbage Collection Bin Overflows Indicator using Internet of Things", Volume 3, Issue 05 May 2016.

[13] Monika K A, Nikitha Rao, Prapulla S B, Shobha G, (2016) "Smart Dustbin-An Efficient Garbage Monitoring System". International Journal of Engineering Science and Computing, June 2016 Volume 6 Issue No. 6 ISSN 23213361 @ IJESC.

[14] Parkash, Prabu, (2016) "IoT Based Waste Management for Smart City”,- International Journal of Innovative Research in Computer and Communication Engineering, Vol. 4, Issue 2, February 2016, ISSN(Online): 2320-9801 ISSN (Print): 2320-9798.

[15] Hong, S. Park, B. Lee, J. Lee, D. Jeong, and S. Park, (2014) "IoT based smart garbage system for efficient food waste management", The Scientific World Journal Volume 2014, Article ID 646953 waste management of Indore city using GIS", International Journal on Emerging Technologies 5(1): 194-200(2014).

[16] Hogland et el. (2007) "Sustainable Waste Management: International Perspectives. Proceedings of the International Conference on Sustainable Solid Waste Management, Chennai, India. 5 - 7 September 2007. pp. $1-8$. 